\title{
Molecular detection and characterization of phytoplasma in association with begomovirus in eggplant
}

\author{
V. VENKATARAVANAPPA ${ }^{1 *}$, H. C. PRASANNA ${ }^{2^{*}}$, C. N. LAKSHMINARAYANA REDDY ${ }^{4}$, M. KRISHNA REDDY $^{3}$ \\ ${ }^{1}$ CHES, Chettalli, Indian Institute of Horticultural Research, Hessaraghatta Lake PO, Bangalore, India; ${ }^{2}$ Indian Institute Vegetable \\ Research, P.O. Jakhini (Shahanshapur), Varanasi-221305, Uttar Pradesh, India; ${ }^{3}$ Indian Institute of Horticultural Research, \\ Hessaraghatta Lake PO, Bangalore-560089, Karnataka, India; ${ }^{4}$ Department of Plant Pathology, College of Agriculture, University of \\ Agricultural Sciences, GKVK, Bangalore-560065, Karnataka, India
}

Received January 3, 2017; revised December 15, 2017; accepted July 3, 2018

\begin{abstract}
Summary. - The samples from eggplants showing mixed symptoms of little leaf and mosaic were collected from two districts (Mirzapur and Varanasi) of Uttar Pradesh, India. The total nucleic acid extracted from these samples was amplified by PCR using universal 16S rRNA primers specific to phytoplasma and primers specific to DNA-A-like sequence of begomovirus. A total of eighteen eggplant samples showing the symptoms of little leaf and mosaic tested positive for the presence of both begomovirus and phytoplasma. The phytoplasma associated with the mixed symptoms of mosaic and little leaf in the eggplant samples was identified as a member belonging to Clover proliferation group (16SrVI) (nucleotide sequence identity of 97.5-97.8\%). The characterized begomovirus from the eggplant samples was identified as a strain of previously described bipartite begomovirus tomato leaf curl Palampur virus (ToLCPalV) (92.5-94.1\% nucleotide sequence identity), which is known to infect cucurbits and solanaceous crops in India and Ireland. Further, putative recombination events were detected within the 16S rRNA gene F2n/R2 fragment of phytoplasma and DNA-A of strain of ToLCPalV. Most of the sequence variations observed within the phytoplasma were due to intra and interspecific recombination events between eggplant little leaf-16SrVI-D, Ca. P. asteris-16SrI and Ca. P. pruni-16SrIII. Similarly, most of the DNA fragments of newly characterized strain of ToLCPalV appear to have been derived from tomato leaf curl New Delhi virus (ToLCNDV), squash leaf curl China virus (SLCCNV) and ToLCPalV like ancestors. This perhaps is the first evidence of mixed infection of both phytoplasma-begomovirus in eggplant in India.
\end{abstract}

Keywords: eggplant; phytoplasma; begomovirus; tomato leaf curl Palampur virus; ToLCPalV; PCR; 16SrVI group

\section{Introduction}

The eggplant (Solanum melongena L.) is cultivated widely in tropical, subtropical and warm temperate countries of the world. It is one of the important vegetable crops in Indian subcontinent and more than $90 \%$ of the world's eggplant is produced in India. The cultivars of the eggplant are highly

*Corresponding authors. E-mail: venkatrajani@gmail.com (V. Venkataravanappa), prasanahc@yahoo.com (H. C. Prasanna); phone: $+8276-266635$.

Abbreviations: SLCCNV = squash leaf curl China virus; Tol$\mathrm{CPalV}=$ tomato leaf curl Palampur virus; ToLCNDV = tomato leaf curl New Delhi virus susceptible to a wide array of pests and diseases. Among the important biotic factors that limit the eggplant production in different regions of the world are phytoplasma and viruses (Pratap et al., 2011a,b; Green et al., 2003, Siddique et al., 2001; Verma et al., 1969). Phytoplasmas are plantpathogenic prokaryotes which belong to the class Mollicutes and cannot be cultured under axenic conditions. They are transmitted in natural conditions by phloem-sucking vectors such as leafhoppers, dodder and psyllids, and could also be transmitted through grafting (Amaral-Mello et al., 2006). In India, the phytoplasma diseases have been associated with more than 45 plant species which include fruit, vegetables, ornamental trees and other agriculturally important crop species (Chaturvedi et al., 2010; Rao et al., 2011). Based 
on $16 \mathrm{~S}$ rRNA sequence analyses, ten diverse groups (16SrI, 16SrII, 16SrV, 16SrVI, 16SrIX, 16SrXI and 16SrXIV) of phytoplasmas associated with diverse crop plant species have been identified in India. Among them, the most commonly associated group are Aster yellows (16SrI), which have been associated with more than 31 plant diseases (Mall et al., 2011) of different cultivated and non-cultivated plants. Mostly, phytoplasmas belonging to different groups have been reported from north-eastern regions of India and very few have been reported from other regions.

On the other end of the spectrum, begomoviruses are known to be responsible for emergence of novel diseases on many agriculturally important crop plants including eggplant. Begomoviruses are circular single stranded DNA plant viruses. These viruses belong to the family Geminiviridae and are transmitted by whiteflies. The genome of the begomoviruses is arranged as a single component (monopartite), or as two separate ssDNA components (bipartite). The component a encodes for several multifunction proteins, which are involved in virus replication, transcription, cell-to-cell and long-distance movement, suppression of host silencing genes, and encapsidation of the viral genome. The component $\mathrm{B}$ plays important role in the movement of virus in the plant, symptom expression and enlarging host range (Lazarowitz, 1992). Their rapid dissemination by whitefly leads to diverse symptom expression (Bull et al., 2004; Varma and Malathi, 2003; Morales and Anderson, 2001). In recent years, new begomoviruses have emerged worldwide, particularly in the areas where Bemisia tabaci population are present in large numbers. Diseases caused by these viruses have become a major constraint in the production of many vegetables and fibre crops in tropical and subtropical countries (Boulton 2003).

The natural co-existence of virus and phytoplasma in the same host plant has been well documented in many crop plants (Franova et al., 2001, 2004; Kaminska et al., 2005; Aljanabi et al., 2008; Parmessur et al., 2002; Lebsky et al., 2011). In the background of this, the roving survey was conducted to assess the incidence of eggplant diseases (mosaic and little leaf) during 2011-2013 at different locations of Mirzapur and Varanasi region in Uttar Pradesh state of India. The infected eggplants under natural conditions exhibited symptoms of leaf curl, little leaf, and combination of little leaf and mosaic which were observed predominately along with the population of whitefly and leaf hoppers. The disease incidence ranged from $35-40 \%$ in different eggplant fields. The distinctive disease symptoms and the presence of whitefly and leaf hoppers on eggplants led us to suspect the possibility of a mixed infection of begomovirus and phytoplasma. Therefore, the present study was carried out to verify the natural co-existence of begomovirus and phytoplasma and to characterize begomovirus and phytoplasma responsible for combined expression of little leaf and mosaic disease symptoms on eggplant.

\section{Materials and Methods}

Survey and collection of disease samples from eggplants. The roving survey was carried out during 2011-2013 in different farmer fields of Varanasi (15 fields) and Mirzapur (7 fields) districts, Uttar Pradesh state of India, to assess the incidence of little leaf and mosaic symptoms on eggplants. The incidence was estimated as percent of diseased plants in each farmer fields based on visual observation. A total of 18 samples of eggplants exhibiting both little leaf and mosaic symptoms were collected from different farmer fields of Varanasi (14 samples) and Mirzapur (4 samples). Sample collection was limited to plants showing typical mixed symptoms of phytoplasma-like little leaf and mosaic. One sample each from both locations without any symptoms of eggplants were also collected. The collected leaf samples were stored at $-80^{\circ} \mathrm{C}$ and used for DNA extraction.

Pathogenicity test using graft transmission. The side veneer grafting was established with scions of the infected eggplant showing combination of mosaic and little leaf symptoms and rootstocks of non-symptomatic seedlings of eggplant cultivar Punjab Barsati. The grafted portion was wrapped with a polythene strip and the scion was covered with a polythene bag. The grafted plants were kept in glasshouse and monitored weekly for the appearance of mosaic and little leaf symptoms.

PCR amplification and characterization of begomovirus. Total DNA of symptomatic and asymptomatic eggplant samples were extracted following Cetyl Trimethyl Ammonium Bromide method (Doyle and Doyle, 1990). The presence of a begomovirus in eggplant samples was detected by PCR amplification carried out using begomovirus genome (DNA-A component) specific primers $2395 \mathrm{~F} / 680 \mathrm{R}$ (Venkataravanappa et al., 2012). These primers bind to the 5 ' region of $\mathrm{AC1}$ (rep), CP gene and intergenic region (IR) (unpublished data). The fragments of $1.2 \mathrm{~kb}$ length amplified using these primers were sequenced. Based on the determined sequences, the begomovirus associated with eggplant was found to be a member of a previously described bipartite begomovirus species ToLCPalV. Therefore, one sample was selected for full-length amplification of begomovirus genomes (DNA-A and DNA-B) by rolling circle amplification (RCA) method performed using an Illustra TempliPhi 100 amplification kit (Amersham Biosciences, USA). Amplification was carried out as per the manufacturer's instructions. The RCA products were digested using different restriction endonucleases (EcoRI, Xba, BamHI and HindIII) and cloned into BamHI-linearized pUC19 plasmid (Venkataravanappa et al., 2016). The ligated products were transformed into competent cells of Escherichia coli DH5a strain. The recombinant clones were confirmed by colony PCR followed by restriction digestion with BamHI and ScaI. The confirmed recombinant clones were sequenced in both orientations at Anshul Biotechnologies Pvt. Ltd DNA sequencing facility, India.

Further to confirm the eggplant samples having subgenomic components, the total DNA extracted from the eggplant samples was amplified by PCR using universal primers of betasatellites beta01/beta02 (Briddon et al., 2002) and alphasatellites (Kumar 
et al., 2010) as described previously for detection of subgenomic components of begomoviruses.

Detection of phytoplasma and sequence characterization. The phytoplasma was detected in eggplant samples using universal primer pair P1/P7 (Deng and Hiruki, 1991; Smart et al., 1996) in the first PCR reaction. This was followed by second round nested PCR amplification using a primer pair R16F2n/R16R2 (Gundersen and Lee, 1996, Lee et al., 1993). Further, the SecY gene was amplified by PCR using SecYF1/SecYR1 (Lee et al., 2010) of eggplant phytoplasma, which has been proven to be useful for fine scale differentiation of phytoplasma strains. All the PCR reactions were carried out for DNA amplification as described by Venkataravanappa et al. (2017). PCR amplified products of 16S rRNA (1.8 kb) and $\mathrm{SecY}$ gene $(1.5 \mathrm{~kb})$ of eggplant phytoplasma were excised from the gel and purified by Qiagen gel extraction kit (Qiagen $\mathrm{GmbH}$, Germany) and cloned into the pTZ57R/T vector (Fermentas, Germany) following the manufactures instructions. Recombinant clones were identified by restriction endonuclease digestion. The selected clones were sequenced as described above.

In-silico enzyme digestion. The F2nR2 fragment of eggplant little leaf phytoplasma was subjected to virtual RFLP analysis using iPhyClassifier (Zhao et al., 2009). The F2nR2 fragment was digested by seventeen restriction enzymes that are used in classification of phytoplasmas into different groups and subgroups (Wei et al., 2008). A virtual gel electrophoresis image (3.0\% agarose) was generated after in-silico restriction digestion. The PCR-RFLP pattern with the key enzymes that distinguish pattern from previously recognized group/subgroup patterns were made in iPhyClassifier. These virtual RFLP gel patterns were used for fine scale differentiation of eggplant strain within the clover proliferation group (16SrVI).

Multiplex PCR for rapid detection of virus and phytoplasma in eggplant. A multiplex PCR assay was optimised for simultaneous detection of phytoplasma and begomoviruses using primers specific to the phytoplasma viz. P1/P7 (Deng and Hiruki, 1991) and R16F2n/R2 (Lee et al., 1993) and begomovirus specific (DNA a region) primer IF1/IR1 (CCCTGAATGTTYGGA TGGAA/ CG GGCGTAGAAATGACGAT). PCR conditions for this multiplex were optimized to ensure sensitive and rapid detection of both phytoplasma and virus (ToLCPalV).

Sequence analysis. Sequence similarity was assessed by comparing sequence of newly characterized begomovirus (DNA-A and DNA-B) and phytoplasma (16S rRNA and SecY gene) to all sequences available in the database (Table 1, 2a and 2b) using BlastN (Altschul et al., 1990). Sequences that showed highest identity with begomovirus and phytoplasma were aligned using the Muscle method implemented in SDT version 1.0 (Muhire et al., 2014) and the sequence identity matrixes for the begomovirus and phytoplasma sequences and the representative sequences were generated. Phylogenetic tree was generated using the Neighbor-Joining method with 1000 bootstrapped replications. The evolutionary distances between all pairs of sequences were estimated using MEGA 6.01 software (Tamura et al., 2013). Split-decomposition trees (as implemented in SplitsTree version 4.11.3) were constructed with 1000 bootstrap replicates to unravel the evidence of recombination in begomovirus and phytoplasma sequences (Huson and Bryant, 2006). Recombination analysis was performed using different methods such as RDP, GENECOV, Bootscan, Max Chi, Chimara, Si Scan and 3Seq that are implemented in RDP4 (Martin et al., 2015).

\section{Results}

\section{Symptoms observed in different eggplant fields}

The roving survey was conducted to assess the viral and phytoplasma mixed disease incidence on eggplants in different farmer fields of Varanasi and Mirzapur region of Uttar Pradesh state. The results revealed that incidence of mixed type of little leaf and mosaic disease symptoms ranged from $35-40 \%$ in different farmer fields. The infected eggplants exhibited diverse symptoms such as mosaic, leaf crinkling, mixture of little leaf and mosaic, little leaf, witches-broom growth, proliferation of lateral buds, hypertrophic calyx and virescent flowers which lack anther and ovary. In all cases the floral buds were malformed into leaf like structure and infected plant failed to set fruits. Infected plants in the fields could be easily recognized from a distance because of their little leaf and bushy appearance. The infected plants were pale green in colour and at the end all little leaves turned into brown and fallen to the ground (Fig. 1).

\section{Detection of phytoplasma}

A total of eighteen eggplant samples showing the mixed little leaf and mosaic symptoms were collected from different farmer fields and initially assayed for the presence of phytoplasma by PCR using universal primer pairs P1/P7 followed by nested PCR using R16F2n/R2 primers. The PCR amplicon of approximately $1.8 \mathrm{~kb}$ and $1.2 \mathrm{~kb}$ size fragment (data not shown) were obtained. Similarly, the SecY gene of eggplant little phytoplasma was amplified using SecYF1/ SecYR1 primer pair to produce amplicon of approximate size of $1.5 \mathrm{~kb}$. There was no amplification in the samples collected from non-symptomatic plants. The amplified PCR products of P1/P7 and SecY gene primers derived from eighteen eggplant samples were sequenced and the sequences of eighteen eggplant phytoplasmas (16SrVI) shared 99\% identity with each other. Therefore, a representative sequence (BLL-2) of 16S rRNA (Acc. No. KC478607) and SecY gene (KX778476) were deposited in GenBank respectively.

Analysis of 16S rRNA and SecY gene sequence of eggplant little leaf phytoplasma

$16 S$ rRNA sequence analysis. Comparison of F2n/R2 primed 16S rRNA gene sequence of eggplant little phyto- 

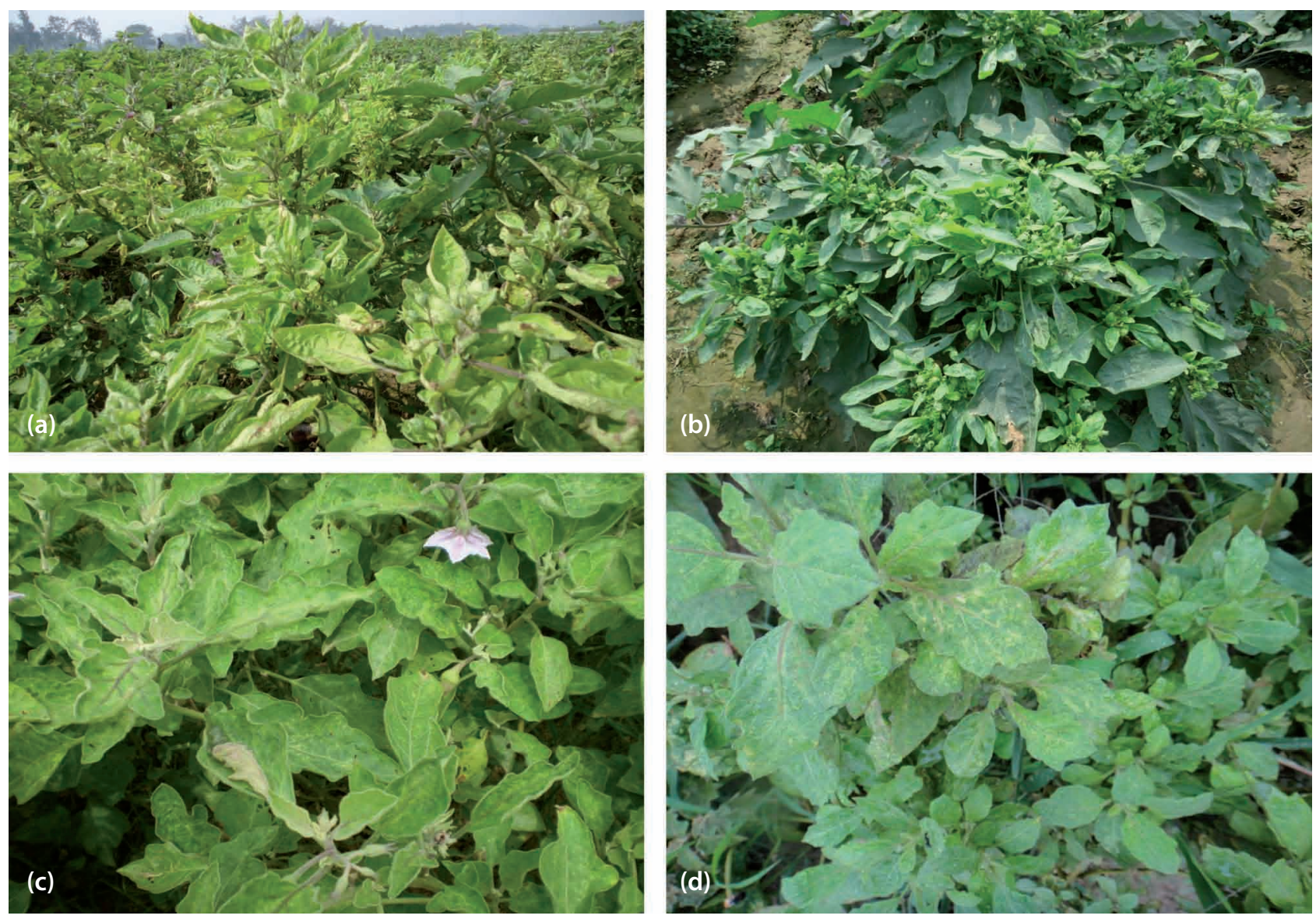

Fig. 1

Symptoms of phytoplasma and TolCPalV in eggplants

(a) Over view of eggplant field showing little leaf symptoms, (b) little leaf phytoplasma, (c) mosaic symptoms, (d) mixed type symptoms of little leaf and mosaic under natural conditions.

plasma (Acc. No. KC478607) with corresponding region of different groups of phytoplasma retrieved from database revealed that the eggplant phytoplasma shared maximum identity in the range of 97.5-97.8\% with subgroup 16SrVI-A belonging to Clover proliferation group (Fig. 2a). Further, the eggplant phytoplasma was compared within the 16SrVI subgroups (A, B, C, D, E, F, G, H, I). It showed sequence similarity of $91.1-93.6 \%$ with $16 \mathrm{SrVI}-\mathrm{B}, 95.2-97.6 \%$ with 16SrVI-C, 95.2-97.6\% with 16SrVI-D, 97.2\% with 16SrVI-E (AY270156), 16SrVI-F (EF186819), 16SrVI-G (AF190225), 96.7\% with16SrVI-H (EF651786) and 95.5\% with 16SrVI-I (GU292081) (Fig. 2a). The threshold level of 16S rRNA sequence identity is set at $94 \%$ for classification of phytoplasma groups into two distinct groups of phytoplasmas (Lee et al., 1993, 2000). The 16 S rRNA gene sequence identity of eggplant phytoplasma characterized here was above the threshold level. Therefore, it is proposed that eggplant phytoplasma should be considered as a member of Clover proliferation group (16Sr VI). This was also supported by a phylogenetic analysis in which 16S rRNA gene of eggplant phytoplasma closely clustered with members of Clover proliferation group (16Sr VI) that infect different crops (Fig. 2).

\section{SecY gene sequence analysis}

SecY gene sequence of eggplant little phytoplasma were compared with the corresponding region of phytoplasmas that belong to different groups (Lee et al., 2010). The eggplant phytoplasma showed maximum nucleotide identity of $94.8 \%$ with Brinjal little leaf-16SrVI-D (GU004356), 94.2\% with Potato witches'-broom-16SrVI-A (GU004316) and 94.1\% with Clover phyllody-16SrVI-A (GU004315) which belong to Clover proliferation group (16SrVI) (Fig. 2b). This result was also supported by a phylogenetic analysis, which showed close affinity between SecY gene of eggplant phytoplasma (GU004356), Vinca virescence-16SrVI-A (GU004317) and Lucerne virescence-16SrVI-A (GU004318) that are members of Clover proliferation group (16Sr VI) (Fig. 2). 


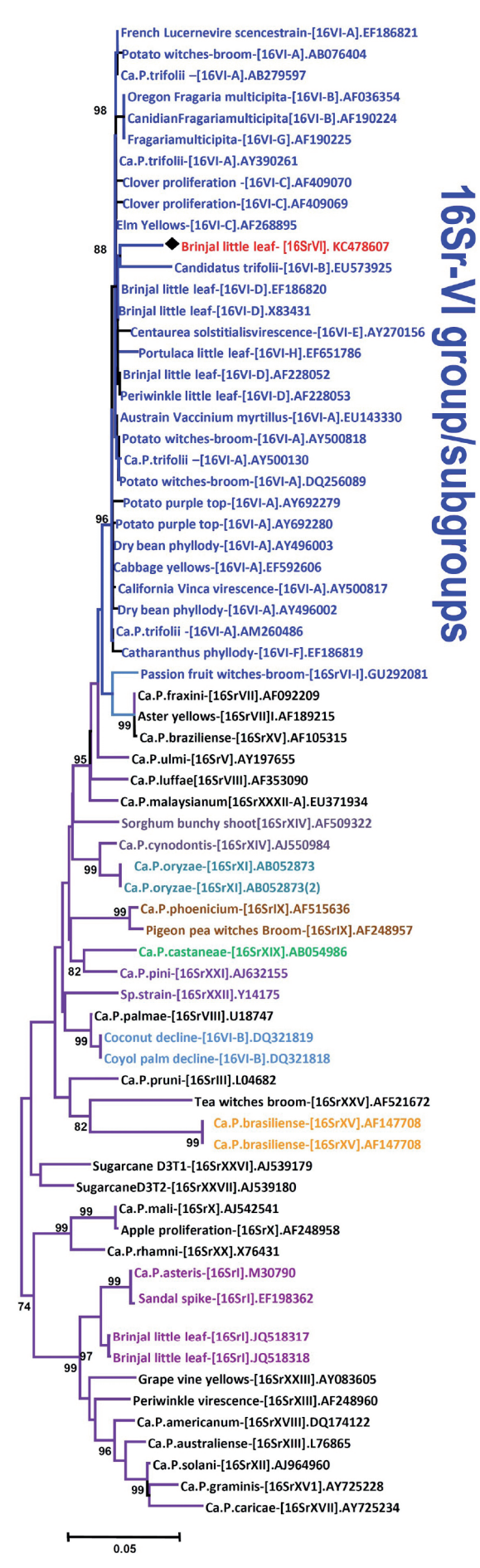

\section{S rRNA gene}

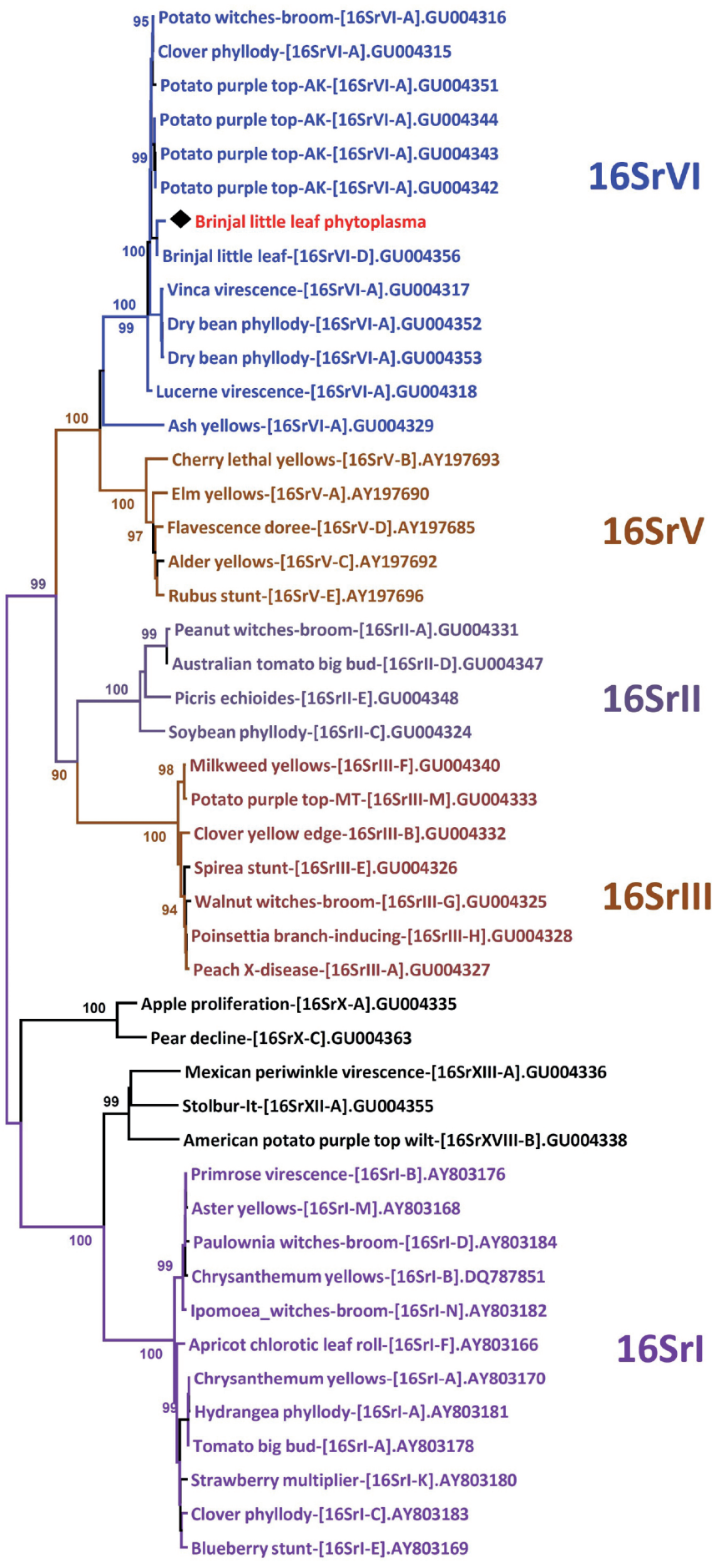

SecY gene

Fig. 2

Phylogenetic tree based on sequences of $16 \mathrm{~S}$ rRNA and SecY gene comparison

$16 \mathrm{~S} r R N A$ and SecY genes from phytoplasma isolated from little leaf and mosaic symptomatic eggplants compared with other phytoplasma strains using Neighbor-joining algorithm. Horizontal distances are proportional to sequence distances, vertical distances are arbitrary. The trees are unrooted. A bootstrap analysis with 1000 replicates was performed and the bootstrap percent values more than 50 are numbered along branches. 

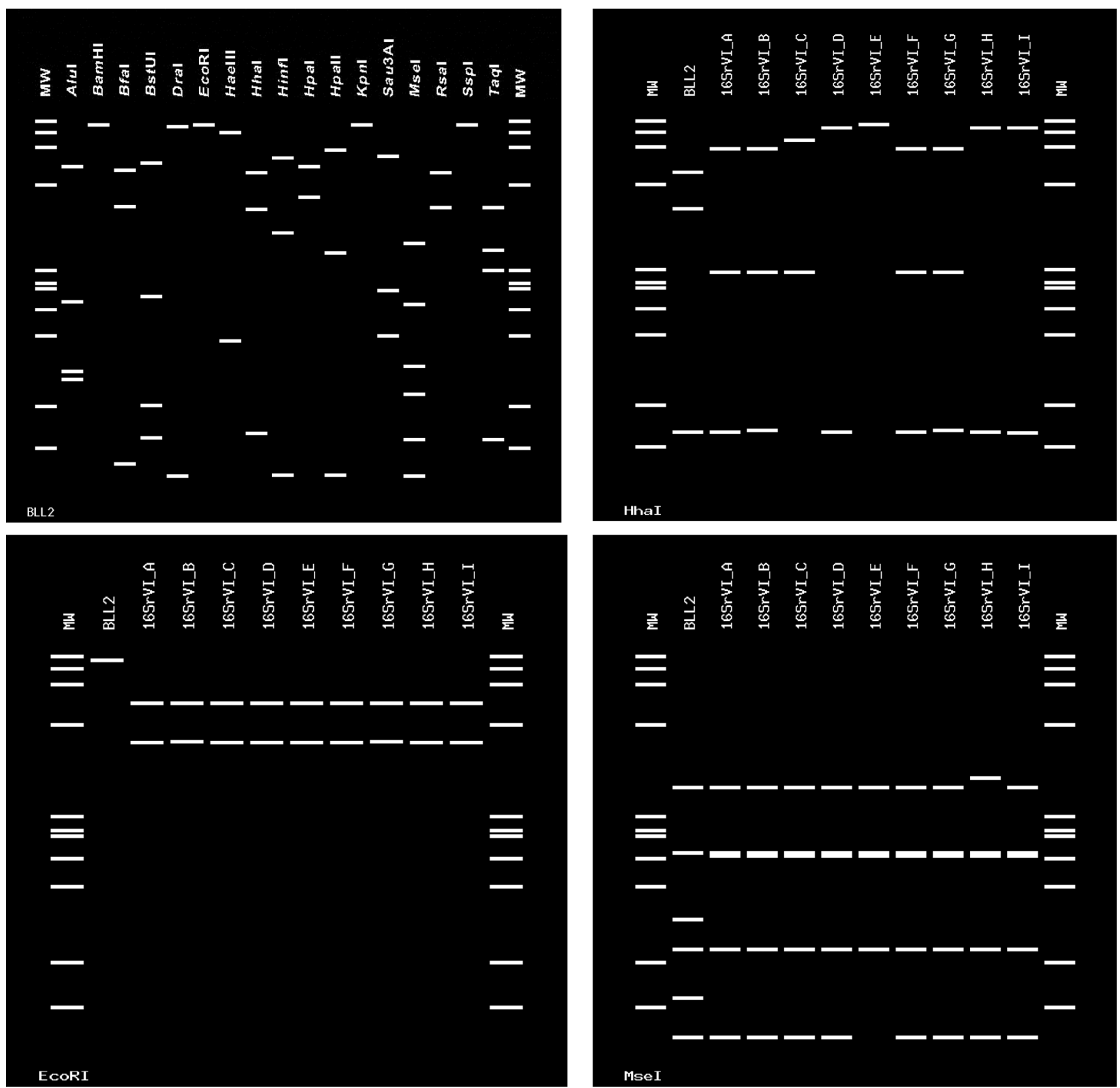

Fig. 3

Virtual RFLP patterns derived from in-silico digestions

RFLP was done using iPhyClassifier, of F2n/R2 fragments of 16S rRNA gene from strain of BLL-2 (Acc. No. KC478607) using 17 restriction endonuclease enzymes (left): AluI, BamHI, BfaI, BstUI, DraI, EcoRI, HaeIII, HhaI, HinfI, HpaI, HpaII, KpnI, Sau3AI, MseI, RsaI, SspI, and TaqI. Virtual RFLP patterns of BLL-MZ (EcoR1, Mse1 and Hha1) were used to distinguish strains of other Indian phytoplasmas from other strains in group 16SrVI. The restriction fragments were resolved by in-silico electrophoresis through 3\% agarose gel. MW = molecular weight marker, WX174 DNA-HaeIII digest.

$16 S$ group/subgroup classification by in-silico enzyme digestion

Virtual RFLP patterns were obtained from in-silico digestions of F2n/R2 fragment from eggplant little leaf phytoplasma using seventeen restriction endonuclease enzymes.
The resultant virtual RFLP patterns of eggplant little leaf phytoplasma were different from previously established 16SrVI groups/subgroups with respect to the three restriction enzymes (EcoRI, MseI and HhaI) (Fig. 3). The pattern had similarity coefficient of 0.86 with the previously reported reference pattern of the 16SrVI group, subgroup D (GenBank 


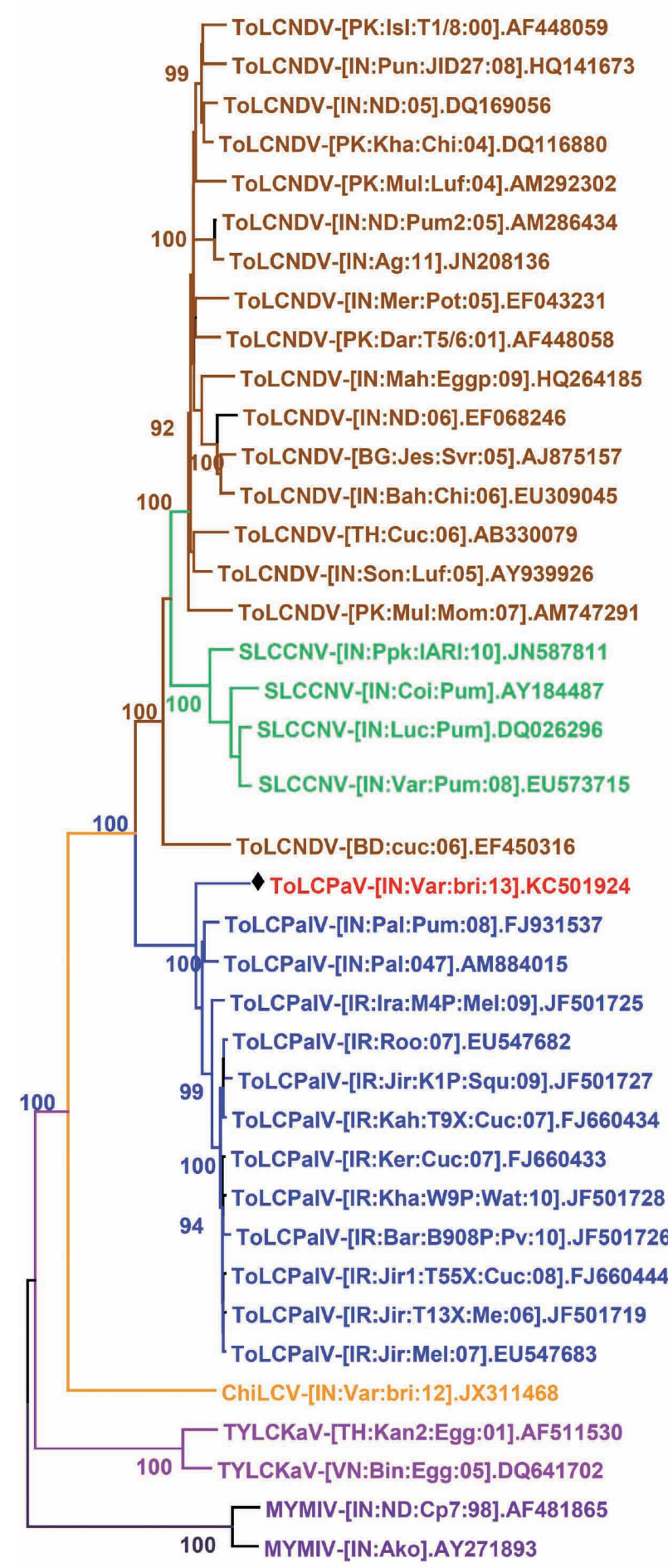

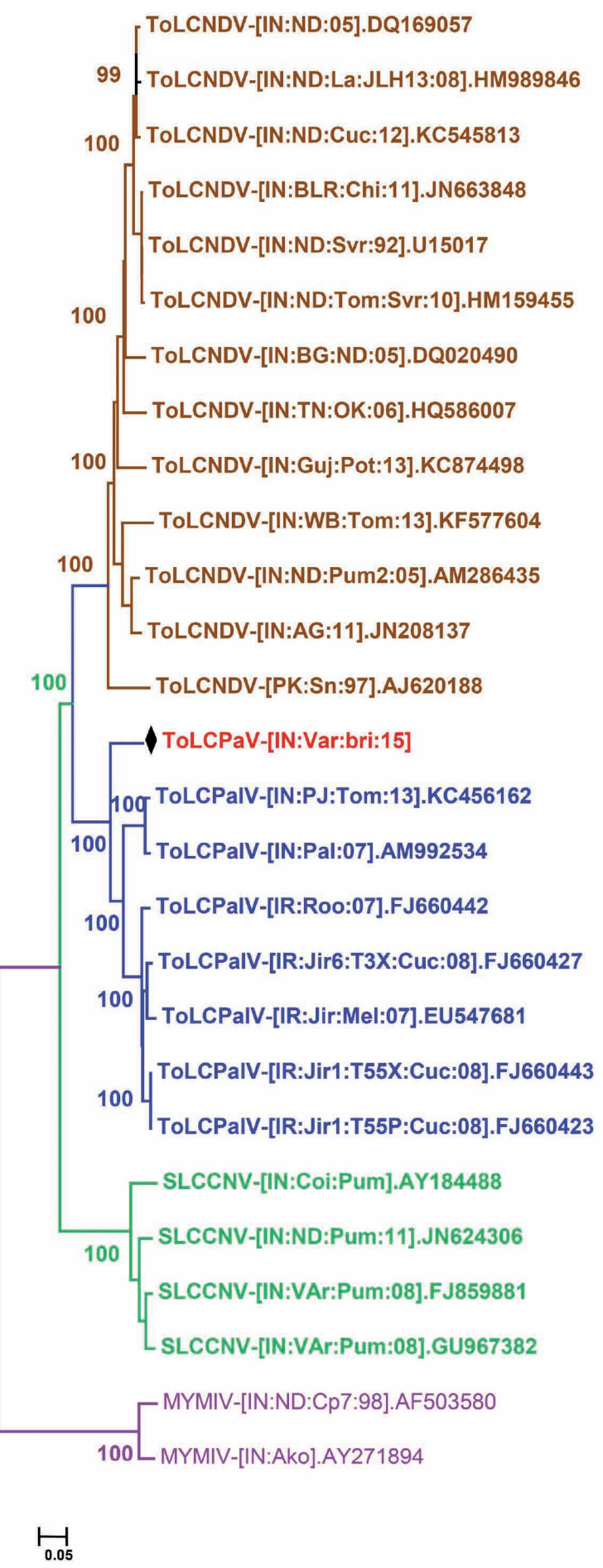

DNA-B

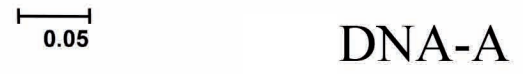

Fig. 4

Phylogenetic trees constructed from aligned complete genomes of DNA-A and DNA-B-like sequences of tomato leaf curl Palampur virus (ToLCPalV) with other begomoviruses using Neighbor-Joining algorithm

Horizontal distances are proportional to sequence distances, vertical distances are arbitrary. The trees are unrooted. A bootstrap analysis with 1000 replicates was performed and the bootstrap percent values more than 50 are numbered along branches. 
Table 1. Pairwise percent of nucleotide identities between the genomic components and amino acid sequence identities of encoded genes from the ToLCPalV [IN:Egg:Var: 13] with the components and genes of selected begomoviruses available in the databases

\begin{tabular}{|c|c|c|c|c|c|c|c|c|}
\hline \multirow{2}{*}{ 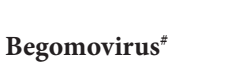 } & \multirow{2}{*}{ Genome } & \multirow{2}{*}{ IR } & \multicolumn{6}{|c|}{ Gene (percentage amino acid sequence identity) } \\
\hline & & & AV2 & $\mathrm{CP}$ & Rep & TrAP & REn & AC4 \\
\hline ToLCPalV-Cuc $(25)^{*}$ & $92.5-94.1$ & $93.7-95.9$ & $94.2-97.3$ & $88.6-91.0$ & $89.9-92.3$ & $96.4-98.5$ & $95.5-96.3$ & $65.5-75.8$ \\
\hline ToLCPalV-Tom (1) & $93.2-93.8$ & 94.5- 95.6 & 96.5- 96.6 & $89.8-91.7$ & $92.0-92.1$ & $98.0-98.4$ & $\underline{96.3-97.0}$ & $72.4-74.1$ \\
\hline ToLCNDV-Cum (14) & $82.3-83.4$ & $77.2-80.2$ & $68.7-77.0$ & $87.1-89.8$ & $78.6-86.1$ & $76.2-84.3$ & $81.6-83.8$ & $68.9-77.5$ \\
\hline ToLCNDV-Tom (10) & $82.5-83.4$ & $78.7-81.3$ & 68.7- 93.7 & $87.5-89.4$ & $83.9-85.5$ & $76.2-82.0$ & $80.8-84.5$ & $67.2-70.6$ \\
\hline ToLCNDV -Pot (4) & $82.4-82.6$ & $78.1-80.6$ & $70.5-73.2$ & $87.1-88.2$ & $85.0-85.3$ & $76.9-82.0$ & $76.9-78.6$ & $67.2-72.4$ \\
\hline ToLCNDV-Chi (4) & $82.6-83.6$ & $79.8-81.0$ & $72.3-74.1$ & $88.6-89.8$ & $85.3-86.1$ & $77.6-81.2$ & $80.8-81.6$ & $70.6-77.1$ \\
\hline ToLCNDV-Egg (1) & 83.2 & 81.2 & 74.1 & 88.6 & 84.2 & 82.0 & 83.0 & 73.0 \\
\hline SLCCNV (5) & $81.0-81.9$ & $75.6-77.4$ & $71.4-72.3$ & $88.2-89.0$ & $83.3-84.7$ & $73.1-73.8$ & $81.6-83.0$ & $58.0-58.6$ \\
\hline TYLCKaV (2) & $68.7-69.1$ & $70.0-70.4$ & $47.0-47.8$ & $71.4-72.2$ & $74.0-75.0$ & $53.7-57.1$ & $60.4-61.0$ & $51.9-55.1$ \\
\hline ChiLCuV-Egg (1) & 73.4 & 71.2 & 68.6 & 88.6 & 74.7 & 55.2 & 58.2 & 62.0 \\
\hline MYMIV (2) & $65.9-67.0$ & $60.9-63.1$ & $44.6-45.5$ & $73.0-74.2$ & $67.0-67.3$ & $42.9-45.1$ & $39.5-41.0$ & $44.8-48.2$ \\
\hline
\end{tabular}

"Numbers of sequences from the databases used in the comparisons. Genes are indicated as coat protein (CP), replication-associated protein (Rep), transcriptional activator protein (TrAP), and replication enhancer (REn). The products encoded by ORFs V2 and C4 have yet to be named. *The species are indicated tomato leaf curl Palampur virus (ToLCPalV), tomato leaf curl New Delhi virus (ToLCNDV), squash leaf curl China virus (SLCCNV), tomato yellow leaf curl Kanchanaburi virus (TYLCKaV), chilli leaf curl virus (ChiLCuV), mungbean yellow mosaic India virus (MYMIV). For each column the highest value is underlined.

Acc. No. X83431 eggplant little leaf phytoplasma). Since the similarity coefficient was much lower than the threshold 0.97 (Wei et al., 2007, 2008), this strain could be considered as new strain that is significantly different from the representative strains of $16 \mathrm{SrVI}$ subgroups.

\section{Detection of begomovirus and sequence analysis}

All the eighteen eggplant samples showing the mixed symptoms of mosaic and little leaf showed positive amplification for DNA-A and DNA-B-like sequence of begomovirus, but not the subgenomic components such as alphasatellite and betasatellites (data not shown). The determined sequences of $1.2 \mathrm{~kb}$ fragments generated from the initial amplification showed that both DNA-A and DNA-B-like sequences in all eighteen eggplant samples are associated with a member of a previously described bipartite begomovirus species (ToLCPalV, nucleotide sequence identity is more than $96 \%$ among the eggplant isolates). Therefore, one representative isolate (BLL-2) was selected for full length amplification of genomic components (DNA a and DNA-B-like sequence) of the begomovirus by RCA method.

The complete genome sequence of begomovirus (BLL-2, Acc. No. KC501924) isolated from eggplants was determined to be $2757 \mathrm{nt}$ in length and genome having a typical Old world (OW) bipartite begomovirus, with six conserved ORFs: AV2 (precoat protein, 120-458/121), AV1 (coat protein, 280-1050/256) in sense orientation; and AC3 (replicase enhancer protein, 1047-1457/136), AC2 (transcriptional activator protein, 1177-1596/139), AC1 (replication associ- ated protein, 1499-2602/367) and AC4 (C4 protein, 2269$2445 / 58)$ in antisense orientation.

The Sequence Demarcation Tool (SDT) analysis of DNAA-like sequence (BLL-2) of eggplant begomovirus (Table 1) showed highest nucleotide identity with tomato leaf curl Palampur virus (ToLCPalV) (92.5-94.1\% nucleotide sequence identity) which is known to infect cucurbitaceous and solanaceous crops in India and Ireland (Table 1). The begomoviruses (ChiLCuV and TYLCKaV) isolated previously from the eggplants share less than $83.2 \%$ identity with the present eggplant isolate. Following the current species demarcation criteria of $91 \%$ nucleotide identity for begomoviruses (Brown et al., 2015), the virus isolated from eggplants in this study is proposed to be strain of tomato leaf curl Palampur virus for which the additional descriptor (India: Varanasi: eggplant: 2013) is suggested. This result was supported by a phylogenetic analysis wherein the eggplant isolate (ToLCPalV) closely grouped with ToLCPalV (Fig. 4).

The complete DNA-B-like sequence (Acc. No. KX778475) of eggplant begomovirus (BLL-2) was determined to be 2724 nt in length and showed maximum nt identity with tomato leaf curl Palampur virus (ToLCPalV) (85.8-89.3\% nucleotide sequence identity) (Table 2). This result is well supported by a phylogenetic analysis wherein the eggplant isolate (ToLCPalV) closely grouped with ToLCPalV that infects different cucurbitaceous and solanaceous crops in India and Ireland. The intergenic region (IR) of isolate (BLL-2) shared 90.3-93.3\% identity with ToLCPalV isolates that are known to infect different hosts (tomato, cucurbits). The IR was found to be $280 \mathrm{nt}$ in length and similar to those 
Table 2. Percent identity of nucleotide sequences and amino acid sequences of different proteins encoded by DNA-B-like sequence of eggplant isolate (ToLCPalV) with those of other begomoviruses selected for the study

\begin{tabular}{|c|c|c|c|c|}
\hline Begomoviruses & Genome $^{\mathrm{a}}$ & $\mathbf{I R}^{\mathrm{a}}$ & $\mathrm{BV}^{\mathrm{b}}$ & $\mathrm{BCl}^{\mathrm{b}}$ \\
\hline ToLCNDV- cucurbits $(9)^{\star}$ & $76.2-78.3$ & $69.1-73.9$ & $75.7-78.7$ & $88.6-93.2$ \\
\hline ToLCNDV- potato (6) & $78.6-79.2$ & $71.5-73.5$ & $78.7-80.2$ & $90.7-91.1$ \\
\hline ToLCNDV- tomato (13) & $76.7-78.3$ & $69.6-72.6$ & $71.0-78.3$ & $\underline{83.6-96.7}$ \\
\hline ToLCNDV- chilli (4) & $78.1-78.5$ & $71.5-75.2$ & $77.9-78.3$ & $88.5-92.1$ \\
\hline ToLCPalV- cucurbits (12) & $84.0-85.0$ & $\underline{90.3-93.3}$ & $88.8-89.9$ & $89.3-91.1$ \\
\hline ToLCPalV- tomato (3) & $\underline{85.8-89.3}$ & $90.0-92.0$ & $\underline{89.5-95.2}$ & $88.6-90.7$ \\
\hline SLCCNV-pum (4) & $70.8-71.4$ & $68.5-70.6$ & $71.6-72.0$ & $84.6-87.1$ \\
\hline MYMIV (2) & $58.5-59.3$ & $58.2-68.3$ & $27.5-29.5$ & $44.0-44.7$ \\
\hline
\end{tabular}

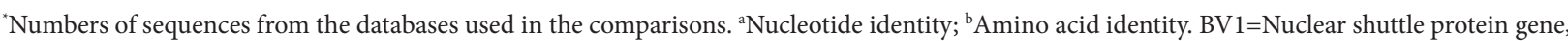

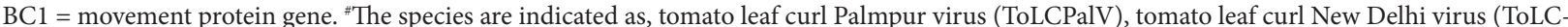
NDV), squash leaf curl China virus (SLCCNV), mungbean yellow mosaic India virus (MYMIV). For each column the highest value is underlined.

of ToLCPalV isolates available in the GenBank. Further, this region encompasses an absolutely conserved hairpin structure with a nonanucleotide sequence (TAATATTAC) that symbolizes the origin of virion-strand DNA replication. The repetitive sequence known as "iteron" (GGAGTC) was detected adjacent to the TATA box that serves as recognition sequence for binding of rep promoter (Arguello-Astorga et al., 1994; Hanley-Bowdoin et al., 1999).

All the eighteen eggplant samples showing the mixed symptoms of mosaic and little leaf were amplified by PCR using universal primer of alphasatellite and betasatellite. The results revealed that none of the eggplant samples were found to be positive for subgenomic components such as alphasatellite and betasatellites (data not shown).

\section{Recombination analysis}

Phytoplasma. The neighbour-net analysis of aligned sequences using split tree program showed extensive networked evolution in 16SrVI groups/subgroups with other groups of phytoplasma. This clearly provided an evidence of recombination (data not shown). The split decomposition analysis also showed a "rectangular" network in which little leaf phytoplasma clustered with 16SrVI groups/subgroups while all other groups of phytoplasma were clearly distant. The separation between little leaf phytoplasma of 16SrVI groups/subgroups and other groups of phytoplasma was clearly revealed in the phylogenetic analysis that resulted in the split graph.

A complete analysis for recombination using RDP4 as well as the alignment of sequences of 16SrVI groups/subgroups and other groups of phytoplasma obtained from database further provided clear evidence for presence of recombination in eggplant little leaf phytoplasma. The analysis showed that Bangladesh Brinjal little leaf (AF228052) and Ca. P. ulmi-16SrV (AY197655) might have contributed genetic material [DNA fragments of 593-907 nt $(\mathrm{P}$-value $=8.13 \mathrm{x}$ $\left.10^{-5}\right)$ ] to the emergence of possible new pathogenic strain of little leaf phytoplasma capable of infecting eggplant.

Begomovirus. A comprehensive analysis for recombination performed using RDP4 and the recombination events detected subsequently are presented in Table 3 . The analysis revealed evidence for recombination in the newly characterised ToLCPalV isolate, with most of the sequences

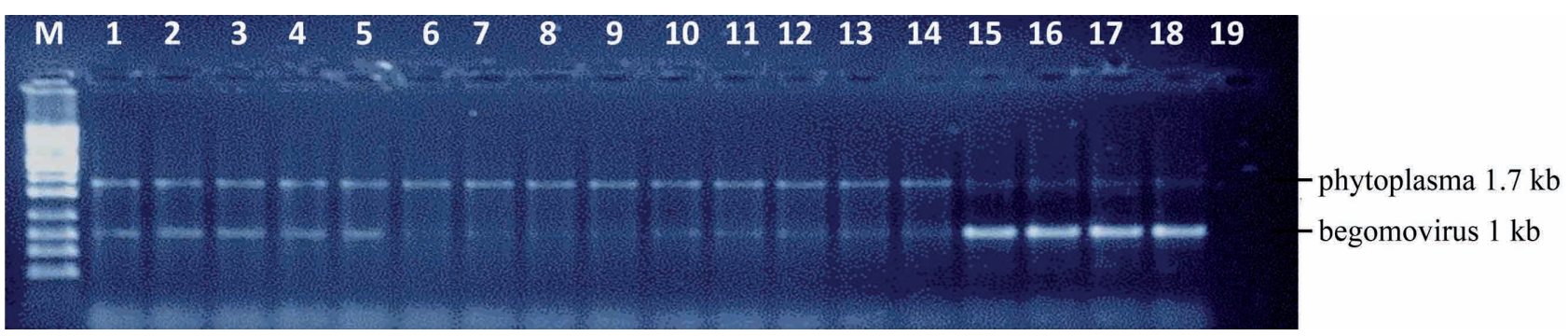

Fig. 5

Multiplex PCR amplification of tomato leaf curl Palampur virus (ToLCPalV) and phytoplasma from eggplants showing the little leaf and mosaic symptoms M: 1 kb ladder; lanes 1-18: phytoplasma and ToLCPalV-positive samples; lane 19: healthy sample. 
originating from ToLCNDV, SLCCNV and ToLCPalV. Similar, analysis was carried out for DNA-B component. The detection of many breakpoints showed larger fragments of putative recombinant origin. The evidence clearly indicates that these segments are derived from the recombination among the ToLCNDV, ToLCPalV and SLCCNV (Table 3). The recombinant sequences in IR region and ORFs of MP and NSP gene of DNA-B component of eggplant strain and begomovirus species provides further evidence to the widespread recombination in begomoviruses.

Graft transmission. Graft transmission was carried out to transmit both virus and phytoplasma. The results revealed that all the twenty grafted (root stock of cultivar Punjab Barsathi) plants showed symptoms of mosaic with pale yellow young apical leaf, which later turned into mosaic symptoms. Similarly, grafted plants showed clear symptoms of little leaf in combination with mosaic (data not shown). In all the grafted plants minimum incubation period was around 2025 days after grafting. Further the presence of phytoplasma and begomovirus in the grafted plant was confirmed by PCR using universal primers (data not shown).

\section{Multiplex PCR for detection of begomovirus and phyto- plasma in eggplants}

The co-existence of virus and phytoplasma under natural conditions is common in many crop plants. Therefore, for simultaneous detection of virus and phytoplasma in eggplants, total DNA of eighteen eggplant samples showing little leaf and mosaic mixed type symptoms was tested by PCR using specific primers of begomovirus and phytoplasma. The resultant PCR amplicon of $1 \mathrm{~kb}$ (ToLCPalV) and 1.5 $\mathrm{kb}$ (phytoplasma Group 16Sr VI) were successfully amplified (Fig. 5) in all eighteen eggplant samples. This test was repeated and further optimized for quick detection of both pathogens in eggplant samples.

\section{Discussion}

Phytoplasmas are responsible for more than 300 distinct plant diseases both in cultivated as well as wild plant species of different families, causing severe economic loss world-wide (Hoshi et al., 2007). The association of complex phytoplasma-virus with many plant diseases has been discussed previously (Arocha et al., 2009). Here we report the new strain of phytoplasma and begomovirus and their association responsible for causing the little leaf and mosaic symptoms on eggplants in India. Based on the sequence analysis of complete nucleotide sequence of begomovirus and $16 \mathrm{~S}$ rRNA gene of phytoplasma, it is certain that the eggplants are infected by tomato leaf curl Palampur virus which belongs to genus begomovirus and phytoplasma 
which belongs to the Clover proliferation group. This perhaps is the first evidence of mixed infection of both phytoplasma-begomovirus in eggplants in India. This type of mixed infection of both phytoplasma and begomovirus was identified in tomato and pepper plants exhibiting yellows symptoms in Mexico (Lebsky et al., 2011). To our knowledge, coexistence of begomovirus and phytoplasmas in eggplants in India or elsewhere has not been reported yet. These types of mixed infections need to be analyzed in more detail for understanding pathogen interactions in the host. The in-silico digestion of F2n/R2 fragments of $16 \mathrm{~S}$ rRNA of phytoplasma using three enzymes (EcoR1, Mse 1 and Hha 1 ) was different from all previously established 16SrVI groups/ subgroups. It has been accepted that difference of even one restriction site (within the 16S rRNA gene F2nR2 region) between phytoplasma strains could be considered as a new subgroup (Lee et al., 1998; Wei et al., 2008). Therefore, we propose the phytoplasma strain isolated from eggplants as new subgroup that differs from those representative strains in other subgroups.

The co-existence of virus and phytoplasma in eggplant samples was successfully detected by multiplex PCR, which is considered more rapid and sensitive for detection of the phytoplasma and the virus. The co-existence of virus and phytoplasma is well documented in many crops. For example, yellow leaf syndrome disease of sugarcane is caused because of the association of sugarcane yellow leaf virus with phytoplasma (Parmessur et al., 2002), phytoplasma and RNA viruses are reported to be associated with premature berry dehydration of grapes (Matus et al., 2008), phytoplasma and Corchorus golden mosaic virus with mosaic and little leaf symptoms in white jute plants (Biswas et al., 2013), coexistence of potyvirus with phytoplasma in clover exhibiting leaf dwarf, curling and diverse drawing symptoms (Franova et al., 2004) and association of potyvirus, tobravirus, nepovirus, tobacco necrosis virus and phytoplasma in common hyacinth causing leaf yellowing and mottle disease symptoms (Navalinskiene and Samuitiene, 2006).

The split-tree analysis showed significant evidence of recombination. The tree clearly substantiated the phylogenetic conflicts in the analyzed sequences. Every sequence represented in the tree was found to be a potential recipient of horizontally acquired sequences. Recombination plays a significant role in generating genetic diversity in prokaryotic and eukaryotic virus populations (Domingo and Holland, 1997; Saunders and Stanley, 1999). In the present study, we observed that the little leaf phytoplasma of eggplants has an intra and inter recombination with most of the 16S rRNA F2nR2 fragments descended from eggplant little leaf-16SrVI-D, Ca. P. asteris-16SrI and Ca. P. pruni-16SrIII, like ancestors. The recombination in extra-chromosomal DNA (EC-DNA) plays a major role in generating genetic diversity in phytoplasma and creates the platform for rapid adaptation to new environmental conditions. The EC-DNA isolated from wild-type line (OY-W) and mild-symptom line (OY-M) of onion yellows phytoplasma encoded a geminivirus like Rep and single-stranded-DNA-binding protein (SSB). The EC-DNA of wild-type line (OY-W) and mild-symptom line (OY-M) has intermolecular recombination between ECDNAs in phytoplasma (Nishigawa et al., 2002). Similarly, recombination is a major driving force in the evolution of geminiviruses (Seal et al., 2006a,b) and the evidence provided in the current study suggests that recombination played a role in the origin of eggplant-infecting ToLCPalV. This new strain of ToLCPalV appears to have derived recombination events from the DNA a of related viruses (ToLCNDV, ToLCPalV, and SLCCNV).

Although the present study provides the evidence for the co-existence of phytoplasma and begomovirus, further studies are required to understand synergism between the virus and phytoplasma in mixed infection under natural conditions. Other factors that include mechanism of coexistence, epidemiological implications and role of geographic location and climate on disease development are required to be studied for managing disease caused by mixed infection of phytoplasma and begomovirus in eggplants.

Acknowledgments. The research was supported by the project "Consortium platform on vaccines and diagnostics" funded by Indian Council of Agricultural Research, Government of India, New Delhi, India.

\section{References}

Aljanabi S, Parmessur Y, Moutia Y, Saumtally S, Dookun A (2008): Further evidence of the association of a phytoplasma and a virus with yellow leaf syndrome in sugarcane. Plant Pathol. 50, 628-636. https://doi.org/10.1046/j.1365-3059 $.2001 .00604 . \mathrm{x}$

Altschul SF, Gish W, Miller W, Myers EW, Lipman DJ (1990): Basic local alignment search tool. J. Mol. Biol. 215, 403-410. https://doi.org/10.1016/S0022-2836(05)80360-2

Amaral-Mello, APO, Bedendo IP, Kitajima EW, Ribeiro LF, Kobori R (2006): Tomato big bud associated with a phytoplasma belonging to group 16Sr III in Brazil. Int. J. Pest Manage. 52, 233-237. https://doi.org/10.1080/09670870600733766

Arguello-Astorga GR, Guevara-Gonzalez LR, Herrera-Estrella LR, Rivera-Bustamante RF (1994): Geminivirus replication origins have a group-specific organization of iterative elements: a model for replication. Virology 203, 90-100. https://doi.org/10.1006/viro.1994.1458

Arocha Y, Pinol B, Acosta K, Almeida R, Devonshire J, Van de Meene A, Boa E, Lucas J (2009): Detection of phytoplasma and potivirus pathogens in papaya (Carica papaya L.) affected with "Bunchy top symptom" (BTS) in eastern Cuba. Crop Prot. 28, 640-646. https://doi.org/10.1016/j. cropro.2009.03.020 
Biswas C, Dey P, Satpathy S (2013): A multiplex nested PCR assay for simultaneous detection of Corchorus golden mosaic virus and a phytoplasma in white jute (Corchorus capsularis L.). Lett. Appl. Microbiol. 56, 373-378. https://doi. org/10.1111/lam.12058

Boulton M (2003): Geminiviruses: major threats to world agriculture. Ann. Appl. Biol. 142, 143. https://doi.org/10.1111/ j.1744-7348.2003.tb00239.x

Briddon RW, Bull SE, Mansoor S, Amin I, Markham PG (2002): Universal primers for the PCR-mediated amplification of DNA beta: a molecule associated with some monopartite begomoviruses. Mol. Biotech. 20, 315-318. https://doi. org/10.1385/MB:20:3:315

Brown JK, Zerbini FM, Navas-Castillo J, Moriones E, RamosSobrinho R, Silva JCF, Fiallo-Olive E, Briddon RW, Hernandez-Zepeda C, Idris A, Malathi VG, Martin DP, Rivera-Bustamante R, Ueda S, Varsani A (2015): Revision of Begomovirus taxonomy based on pairwise sequence comparisons. Arch. Virol. 149, 1193-1200. https://doi. org/10.1007/s00705-015-2398-y

Bull SE, Tsai WS, Briddon RW, Markham PG, Stanley J, Green SK (2004): Diversity of begomovirus DNA $\beta$ satellites of nonmalvaceous plants in east and south east Asia-brief report. Arch. Virol. 149, 1193-1200. https://doi.org/10.1007/ s00705-003-0282-7

Chaturvedi Y, Rao GP, Tewari AK, Duduk B, Bertaccini A (2010): Phytoplasma in ornamentals: detection, diversity and management. Acta Phytopath. Entomol. Hung. 45, 31-69. https://doi.org/10.1556/APhyt.45.2010.1.3

Deng S, Hiruki C (1991): Genetic relatedness between two nonculturable mycoplasma like organisms revealed by nucleic acid hybridization and polymerase chain reaction. Phytopathol. 81, 1475-1479. https://doi.org/10.1094/ Phyto-81-1475

Domingo E, Holland JJ (1997): RNA virus mutations and fitness for survival. Annu. Rev. Microbiol. 51, 151-178. https:// doi.org/10.1146/annurev.micro.51.1.151

Doyle JJ, Doyle JL (1990): Isolation of plant DNA from fresh tissue. Focus 12, 13-15.

Franova J, Mraz I, Petrzik K, Spak J, Sip M (2001): The occurrence of strawberry viruses and phytoplasmas in the Czech Republic. Acta. Hort. 551, 81-86. https://doi.org/10.17660/ ActaHortic.2001.551.13

Franova J, Paltrinieri S, Botti S, Simkova M, Bertaccini A (2004): Association of phytoplasmas and viruses with malformed clovers. Folia Microbiol. 49, 617-624. https://doi. org/10.1007/BF02931544

Green SK, Tsai WS, Shih SL, Rezaian MA, Duangsong U (2003): Molecular characterization of a new Begomovirus associated with tomato yellow leaf curl and eggplant yellow mosaic diseases in Thailand. Plant Dis. 87, 446-446. https://doi.org/10.1094/PDIS.2003.87.4.446A

Gundersen DE, Lee IM (1996): Ultrasensitive detection of phytoplasmas by nested PCR assays using two universal primer pairs. Phytopathol. Mediterr. 35, 144-151.

Hanley-Bowdoin L, Settleage SB, Orozco BM, Nagar S, Robertson D (1999): Geminivirus: models for plant DNA replication, transcription, and cell cycle regu- lation. Crit. Rev. Plant Sci. 18, 71-106. https://doi. org/10.1080/07352689991309162

Hoshi A, Ishii Y, Kakizawa S, Oshima K, Namba S (2007): Hostparasite interaction of phytoplasmas from a molecular biological perspective. Bull. Insectol. 60, 105-107.

Huson DH, Bryant D (2006): Application of phylogenetic networks in evolutionary studies. Mol. Biol. Evol. 23, 254-267. https://doi.org/10.1093/molbev/msj030

Kaminska M, Sliwa H, Rudzinska-Langwald A (2005): Shoot proliferation of bleeding heart (Dicentra spectabilis) associated with phytoplasma and virus infection. Phytopathol. 37, 33-43.

Kumar J, Kumar A, Roy JK, Tuli R, Khan JA (2010): Identification and molecular characterization of begomovirus and associated satellite DNA molecules infecting Cyamopsis tetragonoloba. Virus Genes 41, 118-125. https://doi. org/10.1007/s11262-010-0482-7

Lazarowitz SG (1992): Geminiviruses: Genome and structure and gene function. Crit. Rev. Plant Sci. 11, 327-349. https:// doi.org/10.1080/07352689209382350

Lebsky V, Hernandez-Gonzalez J, Arguello-Astorga G, Cardenasconejo Y, Poghosyan A (2011): Detection of phytoplasmas in mixed infection with begomoviruses: a case study of tomato and pepper in Mexico. Bull. Insectol. 64, 55-56.

Lee IM, Bottner-Parker KD, Zhao Y, Davis RE, Harrison NA (2010): Phylogenetic analysis and delineation of phytoplasmas based on secY gene sequences. Int. J. Syst. Evol. Microbiol. 60, 2887-2897. https://doi.org/10.1099/ijs.0.019695-0

Lee IM, Davis RE, Gundersen-Rindal DE (2000): Phytoplasma: phytopathogenic mollicutes. Annu. Rev. Microbiol. 54, 221255. https://doi.org/10.1146/annurev.micro.54.1.221

Lee IM, Gundersen DE, Davis RE, Bartoszyk IM (1998): Revised classification scheme of phytoplasmas based on RFLP analysis of 16SrRNA and ribosomal protein gene sequences. Int. J. Syst. Bacteriol. 48, 1153-1169. https://doi. org/10.1099/00207713-48-4-1153

Lee IM, Hammond RW, Davis RE, Gundersen DE (1993): Universal amplification and analysis of pathogen 16S rDNA for classification and identification of mycoplasmalike organisms. Phytopathol. 83, 834-842. https://doi.org/10.1094/ Phyto-83-834

Mall S, Chaturvedi Y, Rao GP, Barnwal VK (2011): Phytoplasma's diversity in India. Bull. Insectol. 64, 1721-8861.

Martin DP, Murrell B, Golden M, Khoosal A, Muhire B (2015): RDP4: Detection and analysis of recombination patterns in virus genomes. Virus Evolution 1, vev003 https://doi. org/10.1093/ve/vev003

Matus JM, Vega A, Loyola R, Serrano C, Cabrera S, Arce-Johnson $\mathrm{P}$ (2008): Phytoplasma and virus detection in commercial plantings of Vitis vinifera cv. Merlot exhibiting premature berry dehydration. Electron J. Biotechnol. 11, 7-8. https:// doi.org/10.2225/vol11-issue5-fulltext-8

Morales FJ, Anderson PK (2001): The emergence and dissemination of whitefly-transmitted geminiviruses in Latin America. Arch. Virol. 146, 415-441. https://doi.org/10.1007/ $\underline{\text { s007050170153 }}$

Muhire BM, Varsani A, Martin DP (2014): SDT: A Virus classification tool based on pairwise sequence alignment and 
identity calculation. PLoS ONE 9(9), e108277. https:// doi.org/10.1371/journal.pone.0108277

Navalinskiene M, Samuitiene M (2006): Identification of agents associated with viral and phytoplasmal diseases in common hyacinth (Hyacinthus orientalis L.). Biologija 2, 54-58.

Nishigawa H, Oshima K, Kakizawa S, Jung H, Kuboyama T, Miyata S, Ugaki M, Namba S (2002): Evidence of intermolecular recombination between extrachromosomal DNAs in phytoplasma: a trigger for the biological diversity of phytoplasma. Microbiol. 148, 1389-1396. https://doi. org/10.1099/00221287-148-5-1389

Parmessur Y, Alijanabi S, Saumtally S, Dookun-Saumtally A (2002): Sugarcane yellow leaf virus and sugarcane yellows phytoplasma: elimination by tissue culture. Plant Pathol. 51, 561-566. https://doi.org/10.1046/j.1365-3059 $.2002 .00747 . \mathrm{x}$

Pratap D, Kumar S, Raj SK, Sharma AK (2011a): Agrobacteriummediated transformation of eggplant (Solanum melongena L.) using cotyledon explants and coat protein gene of Cucumber mosaic virus. Indian J. Biotechnol. 10, 19-24.

Pratap D, Ashwin RK, Mukherjee SK (2011b): Molecular characterization and infectivity of a Tomato leaf curl New Delhi virus variant associated with newly emerging yellow mosaic disease of eggplant in India. Virology J. 8, 305. https://doi.org/10.1186/1743-422X-8-305

Rao GP, Mall S, Raj SK, Snehi SK (2011): Phytoplasma disease affecting various plant species in India. Acta Phytopathol. Entomol. Hung. 46, 59-99. https://doi.org/10.1556/ APhyt.46.2011.1.7

Saunders, K, Stanley J (1999): A nanovirus-like DNA component associated with yellow vein disease of Ageratum conyzoides: evidence for interfamilial recombination between plant DNA viruses. Virology 264, 142-152. https://doi.org/10.1006/viro.1999.9948

Seal SE, Jeger MJ, Van den Bosch F, Maramorosch K, Shatkin AJ, Thresh JM (2006a): Begomovirus evolution and disease management. Adv. Virus Res. 67, 297-316. https://doi. org/10.1016/S0065-3527(06)67008-5

Seal SE, van den Bosch F, Jeger MJ (2006b): Factors influencing begomovirus evolution and their increasing global significance: implications for sustainable control. Crit. Rev. Plant Sci. 25, 23-46. https://doi.org/10.1080/07352680500365257

Siddique A, Agrawal GK, Alam N, Krishnareddy M (2001): Electron microscopy and molecular characterization of phytoplasmas associated with little leaf disease of eggplant (Solanum melongena L.) and periwinkle (Catharanthus roseus) in Bangladesh. J. Phytopathol. 149, 237-244. https://doi.org/10.1046/j.1439-0434.2001.00590.x
Smart CD, Schneider B, Blomquist CL, Guerra LJ, Harrison NA, Ahrens U (1996): Phytoplasma specific PCR primers based on sequences of 16S-23SrRNA spacer region. Appl. Env. Microbiol. 62, 2988-2993.

Tamura K, Stecher G, Peterson D, Filipski A, Kumar S (2013): Molecular evolutionary genetics analysis verison 6.0. Mol. Biol. Evol. 30, 2725-2729. https://doi.org/10.1093/ molbev/mst197

Varma A, Malathi VG (2003): Emerging geminivirus problems: a serious threat to crop production. Ann. Appl. Biol. 142, 145-164. https://doi.org/10.1111/j.1744-7348.2003. tb00240.x

Venkataravanappa V, Reddy CNL, Jalali S, Krishna Reddy M (2012): Molecular characterization of distinct bipartite begomovirus infecting bhendi (Abelmoschus esculentus L.) in India. Virus Genes 44, 522-535. https://doi.org/10.1007/ $\underline{\text { s11262-012-0732-y }}$

Venkataravanappa V, Swarnalatha P, Reddy CNL, Neha S, Krishna Reddy M (2016): Association of recombinant Chilli leaf curl virus with enation leaf curl disease of tomato: a new host for chilli begomovirus in India. Phytoparasitica 44, 213-223. https://doi.org/10.1007/s12600-016-0510-9

Venkataravanappa V, Reddy CNL, Swarnalatha P, Shankarappa KS, Krishna Reddy M (2017): Detection and characterization of 'Candidatus Phytoplasma asteris' associated with little leaf disease of bitter gourd from India by $16 \mathrm{~S}$ rRNA phylogenetic and RFLP (in vitro and virtual) analysis. Arch. Biol. Sci. 69, 707-714. https://doi.org/10.2298/ ABS170223017V

Verma A, Chenulu V, Rayachaudhuri SP, Prakash N, Rao PS (1969): Mycoplsama like bodies tissue infected with Sandal Spike and eggplant little leaf. Indian Phytopathol. 22, 289-291.

Wei W, Lee I-M, Davis RE, Suo X, Zhao Y (2008): Automated RFLP pattern comparison and similarity coefficient calculation for rapid delineation of new and distinct phytoplasma 16Sr subgroup lineages. Int. J. Syst. Evol. Microbiol. 58, 2368-2377. https://doi.org/10.1099/ijs.0.65868-0

Wei W, Davis RE, Lee IM, Zhao Y (2007): Computer simulated RFLP analysis of 16SrRNA genes: identification of ten new phytoplasma groups. Int. J. Syst. Evol. Microbiol. 57, 1855-1867. https://doi.org/10.1099/ijs.0.65000-0

Zhao Y, Wei W, Lee I-M, Shao J, Suo X, Davis RE (2009): Construction of an interactive online phytoplasma classification tool, iPhyClassifier, and its application in analysis of the peach X-disease phytoplasma group (16SrIII). Int. J. Syst. Evol. Microbiol. 59, 2582-2593. https://doi.org/10.1099/ ijs. $0.010249-0$ 